\title{
Espinosa, la filosofía en la escuela, y la alegría del pensar
}

Andrea Pac

Universidad Nacional de la Patagonia Austral (Argentina)

\section{Resumo}

O artigo aborda o ponto de vista do pensar como uma 'virtude' em vez de habilidade cognitiva. A noção do pensamento e da alegria em Espinosa é o fulcro de uma concepção não-instrumental da filosofia. A comunidade de investigaçâo da Filosofia com as Crianças é uma prática na que pode-se ver refletida esta inspiração espinosana. Partindo da noção do pensamento como uma expressão da potência essencial de cada indivíduo, são exploradas aqui as noções de diversão e tédio para argumentar que, embora sem garantias, a experiência da filosofia é uma forma de virtude e auto-afirmação do que chamamos espinosamente de alegria do pensar na escola.

Palavras-chave: Pensar, alegria, Espinosa.

\section{Resumen}

El trabajo aborda el punto de vista del pensar como 'virtud' y no como habilidad cognitiva. La noción de pensamiento y de alegría en Espinosa es el punto de apoyo de una concepción no instrumental de la filosofía. La comunidad de investigación de Filosofía con Niños es una práctica en la que se puede plasmar esta inspiración espinosana. A partir de la noción de pensamiento como expresión de la potencia esencial de cada individuo, se exploran aquí las nociones de diversión y de tedio con el fin de argumentar que, aunque sin garantías, la experiencia de la filosofía es una forma de virtud y de afirmación de sí en lo que espinosanamente denominamos la alegría del pensar en la escuela.

Palabras clave: Pensar; Alegría; Espinosa. 


\section{Introducción}

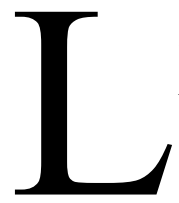

a filosofía suele presentarse como una amiga privilegiada del pensar.

Y pensar es una virtud que nuestras escuelas se proponen desarrollar

en los estudiantes no sólo en términos epistémicos sino también por sus implicancias éticas y políticas. En efecto, la preocupación por desarrollar programas y estrategias para desarrollar 'habilidades de pensamiento' en los niños, adolescentes y adultos que se integran en las diversas etapas y alternativas de los sistemas educativos es constante en las propuestas de las autoridades y los docentes. Entre ellos, la práctica de la filosofía con niños, una de las fuentes de inspiración de este artículo, promueve la relación temprana entre los niños y el pensamiento a través de la discusión filosófica en comunidad de investigación ${ }^{1}$.

Ahora bien, en estas pocas líneas los términos usados plantean ya un aspecto fundamental de la reflexión que proponen estas páginas: desarrollar el pensar como virtud $^{2}$ no es lo mismo que desarrollar habilidades de pensamiento. La diferencia entre estas formas de abordar el pensar en la escuela y su relación con la filosofía, no reside en que se trate de funciones ni de operaciones diversas. Precisamente, mientras que por lo general el énfasis descansa en el punto de vista de las funciones y las operaciones, lo que aquí propongo es adoptar unos supuestos y una perspectiva -si se me permite, un espíritu- diferente, esto es, el punto de vista del pensar como virtud, como potencia.

\footnotetext{
${ }^{1}$ Esta práctica se apoya en el Programa Philosophy for Children que, actualmente, se desarrolla en muchos países, con las adaptaciones y variaciones inevitables. Vale advertir que en las descripciones de las tareas a llevar a cabo en el aula de las que aquí se hablará, se reconocerán rasgos de esta práctica y de sus supuestos teóricos. Algunos textos básicos sobre este programa traducidos al español: Lipman, 1992 y Splitter; Sharp, 1995.

${ }^{2}$ Vale aclarar que se utilizará aquí la palabra 'virtud' despojada de todo matiz moral y con un sentido espinosano, como quedará claro más adelante.
}

Filosofia e Educação - ISSN 1984-9605 - Volume 5, Número 1

Abril - Setembro de 2013 
En ese sentido, no se ofrecerán aquí reflexiones ni fundamentaciones de tipo pedagógico o metodológico sobre el papel de la filosofía en las escuelas. No me referiré a la importancia de la filosofía para enseñar o aprender a pensar, o para el desarrollo del pensamiento crítico, ni para la constitución de ciudadanos tolerantes y responsables. El pensar como virtud, para decirlo de una vez, remite a la filosofía de Espinosa, para quien pensar no es una habilidad cognitiva sino la expresión de la potencia que constituye la esencia de cada individuo. En ese marco, este trabajo tratará de la alegría del pensar: una alegría que suele ser postergada por la exigencia del desarrollo de las habilidades, o por la urgencia de la defensa de nuestra fuente de trabajo frente a la amenaza de alguna nueva reforma educativa, o por la meticulosidad de los informes escolares y la presión de la burocracia institucional; una alegría que hasta nosotros, los docentes, corremos el peligro de olvidar y cuyo disfrute, en consecuencia, vedamos a nuestros alumnos (de manera que, en ocasiones, finalizan su proceso de escolarización sin siquiera sospechar las felicidades que, como buena amante, la filosofía ofrece y oculta en un único gesto).

En lo que sigue, pues, propongo tomar en serio la alegría del pensar. Para ello, en primer lugar, pagaré mi deuda con Espinosa por el concepto de alegría y su relación peculiar con el pensamiento. En segundo lugar, recurriré a las reflexiones de Pascal sobre lo aburrido y lo divertido con el fin de aportar a las posibilidades del pensar en ese sentido. Finalmente, concluiré con una reflexión sobre la alegría de compartir la filosofía como parte de la tarea educativa.

\section{Espinosa y la alegría como potencia de ser}

Espinosa es un filósofo de la alegría. Más aún, se ha llegado a considerar su filosofía como un eudemonismo (Misrahi, 1992), tanto por el contenido de su 
Ética como por la vivencia que, para algunos lectores, acompaña al estudio de su obra. En este sentido, se ha dicho que al sistema de Espinosa subyace una experiencia de la felicidad a la cual es difícil sustraerse cuando se lee la obra con intensidad ${ }^{3}$. La alegría como concepto y como experiencia es sin dudas una de las claves de la ética espinosana. Y la relación de la alegría con la experiencia del pensar, es lo que se rescatará a continuación.

En ÉIII11cor', la alegría es definida como "[un afecto] por [el] que el alma ${ }^{5}$ pasa a una mayor perfección" (y que, cuando involucra tanto al alma como al cuerpo, es placer ${ }^{6}$ ). La esencia de todos los cuerpos y de todas las almas consiste en una determinada potencia que se expresa como capacidad de actuar y de pensar (cf. ÉIII6 y ss). Pero esta potencia no es inmodificable sino que puede aumentar o disminuir, pasar a una perfección mayor o menor, en los sucesivos encuentros con objetos e ideas exteriores. Por ejemplo, un encuentro entre nuestro cuerpo y un alimento aumenta su potencia de obrar y produce alegría (y, en algunos casos, también placer); un encuentro con un veneno, por el contrario, lo enferma, reduce su potencia de obrar. Lo mismo sucede cuando se consideran las ideas de estos objetos como si ellos mismos estuvieran

3 “... la filosofía spinozista no exige, como una conclusión, una cierta concepción de la felicidad. Ella misma no es sino el punto de llegada, la elaboración y la culminación de una experiencia de felicidad que la preexiste, o más bien un deseo absoluto de felicidad respecto del cual la filosofía de Spinoza no es así más que la superestructura intelectual, la cristalización inteligible" (Henry, 2008, 34).

${ }^{4}$ Se citará esta obra por la traducción al español de Vidal Peña y la de Atilano Domínguez.

${ }^{5}$ A pesar de que el término latino que usa mayoritariamente Espinosa es mens, al hablar sobre su filosofía se suele mantener el término 'alma', que también mantendremos aquí.

${ }^{6}$ En general, en este artículo se mantendrá el énfasis en el punto de vista de la alegría. No obstante, téngase en cuenta que la tristeza es definida en el mismo sitio que la alegría como "una pasión por la que el alma pasa a una menor perfección", que referida también al cuerpo es dolor o melancolía (ÉIII11esc). Asimismo, cabe agregar que como consecuencia de estas concepciones de la alegría y de la tristeza, cuando consideramos que un objeto es causa de nuestra alegría, lo amamos e intentamos conservarlo, mientras que cuando consideramos que un objeto es causa de nuestra tristeza, lo odiamos e intentamos destruirlo (ÉIII13esc).

Filosofia e Educação - ISSN 1984-9605 - Volume 5, Número 1

Abril - Setembro de 2013 
presentes. Así, cuando imaginamos (tomamos como presente) algo que nos alegra, es posible sentir ya esa alegría, y pasa ya el individuo a una mayor perfección (cf. ÉIII12): la imagen de un descanso reparador puede ser un estímulo más para completar una jornada intensa de trabajo. Asimismo, como consecuencia de que la alegría está asociada a una causa (que, en principio, suele ser un objeto externo), cuando imaginamos que algo es causa de la alegría, lo amamos; de modo que el amor es una alegría, acompañada por la idea de un objeto exterior como su causa (ÉIII13esc $)^{7}$.

Ahora bien, ¿cómo se resignifican estos estos conceptos en términos de la tarea del aula y de la investigación filosófica en la escuela? Cabe subrayar que no siempre las causas de la alegría son objetos exteriores. Ser capaces de superar una prueba física es una experiencia de la potencia de obrar propia del cuerpo $\mathrm{y}$, en consecuencia, una alegría. Así también, superar una prueba intelectual o simplemente experimentar que podemos concebir ideas es una alegría porque así se percibe en sí mismo la eficacia de la potencia de pensar ${ }^{8}$. Lo que caracteriza a las actividades que se hacen en el aula, es que la mayoría de éstas (por no decir la totalidad) no dependen de objetos exteriores sino de nosotros mismos y, por ello, pueden expresar grados de potencia cuyo aumento depende de sí mismo como causa. Y, considerarse a sí mismo como causa de la propia alegría es equivalente a considerar la propia potencia, lo cual puede dar lugar a una alegría sólida y duradera, mucho más de la que surge de la comparación de la potencia propia con la de los demás. Precisamente, en el escolio de la proposición donde Espinosa trata de este contento de sí (ÉIII55), observa que la educación contribuye a la inclinación de los hombres al odio y la

7 También el odio es definido en esta proposición, como la idea de una cosa exterior como siendo causa de tristeza.

${ }^{8}$ Por eso mismo, la confusión es una tristeza porque experimentamos nuestra impotencia. 
envida "pues los padres suelen incitar a los hijos a la virtud con el solo estímulo del honor y la envidia”, esto es, con el solo estímulo de la competencia y no de la consideración de sí mismos.

Pensar es alegría porque el pensar mismo es la potencia del alma, como actuar es expresión de la potencia del cuerpo. Cuando el hombre piensa, experimenta su potencia, siente contento de sí, y también experimenta que puede hacerla crecer, puede afirmarse a sí mismo en su pensamiento. Para Spinoza, esto tiene una correlación en el cuerpo dado que no es posible que el alma actúe sin que al mismo tiempo lo haga el cuerpo ${ }^{9}-\mathrm{y}$, sin faltar a la verdad, se puede decir que uno siente un entusiasmo físico también cuando piensa.

Pero no se trata de pensar de cualquier manera. Hay formas de pensar que no alegran sino que entristecen, esto es, formas de pensar en las que uno experimenta su impotencia en lugar de afirmarse en sí mismo. Como se dijo más arriba, la confusión es una forma de la impotencia. La inseguridad con respecto al resultado que obtendremos en el examen para el que estudiamos produce tristeza. No encontrar sentido a las actividades que se realizan en la escuela es una forma de no descubrir de qué manera la potencia de pensar puede ser aumentada en ese ámbito y, en consecuencia, es también una tristeza.

Un pensar que comprende, que aprehende las relaciones de las cosas entre sí y con sí mismo, las relaciones del sí mismo con el todo y de las partes del todo entre sí, es un pensar seguro y con sentido. Aun cuando no alcancemos el máximo grado de conocimiento en términos espinosanos (la perspectiva de la eternidad), si el pensar es genuino, se asienta en nosotros como un grado constante de la potencia propia que ha crecido, que podemos hacer crecer más y que asegura que el pensamiento no es vacuo sino real. Y, si hay un rasgo del

${ }^{9}$ Más aún, en un sentido, la potencia de pensar del alma depende de la aptitud de actuar, de “afectar y ser afectado" del cuerpo, cf. ÉII14 y ÉV39.

Filosofia e Educação - ISSN 1984-9605 - Volume 5, Número 1

Abril - Setembro de 2013 
pensamiento de Spinoza que los docentes no debemos olvidar, ése es que cualquier aumento de perfección es alegría, y cualquier pensamiento en el que se constate tal aumento es alegre. Tal vez no exista una definición más exacta de este pensar que comprende que la firmeza que conlleva la experiencia de él que algunos hayamos tenido alguna vez; pero tampoco existe un modelo de perfección que los individuos deban alcanzar.

Sin embargo, los docentes confundimos con frecuencia los 'objetivos' que nos proponemos con modelos de perfección que, en el fondo, son vacíos ${ }^{10}$. Por éste, y otros motivos que fueron mencionados más arriba, olvidamos la alegría que es pensar y, por decirlo en términos cotidianos, la escuela -y la filosofía no escapa a esta generalización- resulta aburrida. $\mathrm{O}$, al menos, se nos reclama a los docentes que no hacemos actividades divertidas, llamativas, que interesen a nuestros estudiantes. ¿Cómo enfrentar este reclamo, cuando se tiene la convicción de que pensar es la misma alegría?

\section{Lo divertido, lo aburrido y la alegría}

Las nociones de lo divertido y lo aburrido son, sin dudas polémicas. Y, cuando se intenta definirlas a partir de ejemplos de las actividades que las personas suelen encontrar divertidas o aburridas, la diversidad de criterios suele resultar por lo menos frustrante. Es necesario, pues, recurrir a fuentes menos parciales que los gustos de unos y otros para pensar sobre lo divertido.

Si nos preguntamos por el sentido etimológico de la palabra, descubrimos que 'divertir' viene de verter en su forma divertere que, hacia fines del siglo XVI significa 'apartarse', distraer la atención de una cosa para atraerla hacia

\footnotetext{
${ }^{10}$ En este sentido, no estoy de acuerdo con Boss, quien sostiene que la comparación con la idea de perfección es la que hace posible la experiencia de la alegría o la tristeza (cf. Boss, 1994).
}

Filosofia e Educação - ISSN 1984-9605 - Volume 5, Número 1

Abril - Setembro de 2013 
otra. Un siglo después, adopta el sentido de diversión familiar para nosotros, en el cual aquello hacia lo que se conduce la atención es algo que provoca risa o alborozo. Por su parte, aburrir viene del latín abhorrere, que significa 'tener aversión a algo, aborrecer', y hacia el siglo XVI adopta ya el sentido con que lo usamos actualmente, opuesto a la diversión (cf. Corominas; Pascual, 1991).

Esta breve referencia etimológica da lugar a algunas observaciones interesantes. En primer lugar, se nota que tanto divertir(se) como aburrir(se) implican una desviación, una derivación del ánimo, ya sea mediante un apartamiento de algo (como es claramente el caso en el aburrir) o acercamiento hacia algo (como resulta más marcado en el divertir). En cualquier caso, ambas son formas de alejarse de alguna cosa: en el aburrimiento, del objeto o situación que causa ese efecto en nosotros; en la diversión, de cualquier cosa o situación que, comparado con otro, resulta menos atrayente. En este sentido, abhorrere es equivalente al odio, tal como es definido por Espinosa en ÉIII13esc.

En segundo lugar, se observa que, en el sentido en que se usa actualmente, el énfasis está puesto en el objeto y no en el ánimo: en efecto, son muy específicos los momentos en los que uno dice 'estoy aburrido', a diferencia de la cantidad de objetos o actividades de las que se dice 'son aburridas' o 'son divertidas'. Dicho en otras palabras, se suele poner el acento en el objeto exterior como causa de la aversión o la atracción, antes que en los estados del ánimo en sí mismos (y, bien pensado, son situaciones bastante diferentes entre sí). De este modo, los objetos son el centro y la causa del aburrimiento y la diversión, de la misma manera en que los objetos exteriores pueden ser el centro y la causa de la alegría y la tristeza en sus formas menos sólidas. 
Veámoslo ahora en términos filosóficos. Desde este punto de vista, la diversión no goza de prestigio, precisamente. Tomemos, por ejemplo, a Pascal. En sus reflexiones sobre la diversión se pregunta ${ }^{11}$ :

¿A qué se debe que este hombre, tan afligido por la muerte de su mujer y de su hijo único, tan atormentado por un pleito muy importante, en este momento no esté triste, y se lo vea liberado de todos esos pensamientos penosos e inquietantes? No hay que asombrarse; terminan de enviarle una pelota y debe lanzarla a su compañero, está ocupado en tomarla a la caída del techo para ganar un punto; ¿cómo pretendéis que piense en sus asuntos, ahora que tiene este otro asunto entre manos? (Br140).

La diversión, que está en el fondo de este fragmento, es una ocupación y una distracción. Podríamos pensar que Pascal es un poco injusto con el hombre de su fragmento. Si sólo de ocuparse y distraerse se tratara, en lugar de una pelota, el personaje podría tener entre manos un libro. Sin embargo, se verá que no es así. La pintura que aquí delinea Pascal tiene un supuesto muy preciso: la diversión distrae del tedio, ese estado del ánimo en el que se incurre cuando no tenemos una ocupación específica. Y es muy necesario para el hombre evitar el tedio, dado que cuando no tiene en qué ocupar su mente

...siente su nada, su abandono, su insuficiencia, su dependencia, su impotencia, su vacío. Al instante extraerá del fondo de su alma el tedio, la negrura, la tristeza, el pesar, el despecho, la desesperación (Br131).

Por supuesto, en este sentido, divertirse es humano. Sería absurdo condenar a una persona por querer evitar la consideración de su desamparo, de su impotencia y de su pequeñez. El tedio es un peso excesivo para cualquiera y no es ciertamente por reaccionar contra él que la diversión es objetable. Pero Pascal observa que al evitar la experiencia de la propia insignificancia mediante la diversión, se busca el remedio para la angustia que provoca el aburrimiento

\footnotetext{
${ }^{11}$ Los fragmentos de los Pensamientos serán citados según la numeración de Brunschvicg.
} 
en el lugar equivocado. ${ }^{12}$ Por otro lado, Pascal considera que la diversión adolece de una limitación insuperable porque persigue un objeto exterior para enfrentar un estado del ánimo. En consecuencia, al depender de esos objetos exteriores y variables, el olvido del aburrimiento que posibilita es aparente y efímero. En este sentido, argumenta:

¿pero no constituye una felicidad el poder ser regocijado por la diversión? -No, porque ella proviene de otra parte y de afuera; por lo tanto, es dependiente y puede ser turbada por mil accidentes, los cuales generan las aflicciones inevitables (Br170).

Así pues, la diversión es aburrida: en tanto que consista solamente en un aturdirse, en un distraerse, la diversión no nos permite despegarnos de la tristeza que despierta en nosotros el aburrimiento. La diversión nos aleja unos pasos de aquello que nos aburre y de lo que por tanto queremos alejarnos; pero no es más que un desvío en el camino que, inexorablemente, nos devuelve a la orilla del abismo. El estado de ánimo que es el tedio no se modifica, permanece en nosotros, esperando que termine el juego.

Cabe aclarar que, para Pascal, la filosofía es apenas una forma más de la diversión (una razón más por la que no es especialmente injusto con el hombre del fragmento 140), y sólo la eligen los hombres cuya ceguera no les permite percibir la ridiculez de su razón. En términos pascalianos, pues, jugadores de pelota y filósofos se igualan en el ansia de evitar el abismo del sí mismo y en tomar para ello un camino equivocado, por estar desviado de la gracia. Ambos se debaten con un estado del ánimo que ningún objeto puede mitigar (el aburrimiento), ni asegurar (la diversión).

\footnotetext{
${ }^{12}$ Recuérdese que éste es un pensador católico que considera que la única forma de evitar el abismo que acecha en el fondo de la condición humana es la fe.
} 
No obstante, a pesar del escepticismo pascaliano, el pensar es algo más que diversión. Podemos estar de acuerdo en que el tedio o el aburrimiento se nos aparecen como la apertura de un abismo. En efecto, si tras el aburrimiento se cierne el sinsentido, bien se puede aborrecer ese estado de ánimo. Pero también son aborrecibles, en el fondo, los objetos que engañosamente prometen evitarlo en la diversión. Nos encontramos, así, en una situación similar a la que Espinosa describe al comienzo del Tratado de la Reforma del Entendimiento: los bienes que prometen felicidad, son la misma causa del dolor y la inquietud (cf. TRE2-9). Pero, si de enfrentar el tedio se trata, el pensamiento no se limita a disimular el abismo sino que o bien nos permite afirmarnos a pesar de él, o bien es un lugar seguro desde donde reconocerlo, un puerto seguro a partir del cual recorrerlo y abordar el sinsentido. Por otra parte, como dice Espinosa, el pensar no es 'dependiente', no puede ser 'turbado por mil accidentes', como la diversión.

Por otra parte, aquello que imaginamos ser causa de nuestra alegría es, como se dijo más arriba, objeto de amor. Los hombres, sabe Espinosa, pueden amar muchas cosas. Pero de todas ellas, el pensamiento es una de las más perfectas -no en vano es un filósofo. A diferencia de amar a una persona, a un automóvil último modelo u otros objetos por el estilo, amar el pensamiento no puede jamás implicar tristeza (porque el pensamiento mismo es potencia). Tampoco puede provocar tristezas entre los hombres del tipo de la envidia ${ }^{13} \mathrm{o}$ los celos ${ }^{14}$, producto de la competencia por la exclusividad en el disfrute de los objetos amados. Si estas pasiones son provocadas en alguien por el conocimiento, es porque en el fondo lo que persigue es, por ejemplo, la gloria

${ }^{13}$ Ésta consiste en "el odio mismo, en cuanto considerado como disponiendo al hombre a gozarse en el mal de otro, y a entristecerse con su bien" (ÉIII24esc).

${ }_{14}$ Éstos consisten en el "odio hacia una cosa amada, unido a la envidia" por el otro que se alegra en el disfrute de la cosa amada (ÉIII35esc).

Filosofia e Educação - ISSN 1984-9605 - Volume 5, Número 1

Abril - Setembro de 2013 
(o sea, la alegría de creerse alabado por los demás, ÉIII30esc) antes que el pensar como expresión de su potencia. Pero si realmente ama el conocer, no puede sentirse humillado ni avergonzado como consecuencia de su pensar, ni tampoco puede ensoberbecerse ${ }^{15}$.

Se sigue de aquí que el pensar con otros, tal como se persigue llevar a cabo en comunidad de investigación, nos hace amigos pero no por simpatías personales, sino porque es algo que, al ser compartido, sólo puede implicar alegría compartida. El remedio para el aburrimiento, pues, no es la diversión sino la alegría -en lo que aquí nos ocupa, la alegría del pensar.

\section{Compartir la filosofía... ¿en la escuela?}

Desde ya, cuando se dice que la escuela es aburrida, no se tienen en mente los argumentos de Pascal. Muchas veces, el aburrimiento es un nombre que se da a la dificultad; otras, remite a las actividades repetitivas, uniformes y uniformizantes (y en este punto, el calificativo está justificado). Pero también la escuela puede ser aburrida porque las actividades en el aula se esfuerzan por ser divertidas, pero no alegres.

Por un lado, son muchos los aspectos de las instituciones escolares que contribuyen a ello: desde los edificios, cuya arquitectura es abiertamente fea (y esto si los vidrios están sanos y las puertas en su lugar), hasta la burocratización tanto de la enseñanza como del aprendizaje. En este contexto, el pensar deja de ser una virtud, y se transforma en un ítem más de la planilla de calificaciones de los estudiantes, en un gesto más de los que hay que aprender a hacer a tiempo, aun cuando se trabaje en comunidad de investigación: saben que preguntar 'por

15 Estos afectos son, en definitiva, formas de la impotencia: la humildad (ÉIII29 y ÉIIIDefAf43); la vergüenza (ÉIII30esc y ÉIIIDefAf31); la soberbia (ÉIII26esc y ÉIIIDefAf28).

Filosofia e Educação - ISSN 1984-9605 - Volume 5, Número 1

Abril - Setembro de 2013 
qué' en determinado momento, contar una anécdota como ejemplo, manifestar desacuerdo con un mínimo fundamento es anotado por el docente como 'pensar' y tiene su calificación correspondiente. Por esta razón, se trata de un pensar sin alegría.

Debo decir, no obstante, que no es sencillo que acontezca el pensamiento alegre. No existe un método para producir alegría del pensar, ni tal vez una descripción precisa de ella (como se apuntó más arriba). De hecho, sospecho que justamente de la perspectiva del método resulta un pensar sin alegría. Sólo sé que, a veces (porque la verdad es que no siempre sucede), cuando alguien en el aula -un estudiante o yo misma- rescata su propia alegría de pensar, algunos se contagian y ocurre la magia. Y alcanza con que ocurra una vez para guardar el recuerdo de la alegría e intentar reeditarla en otra oportunidad. Los textos de los filósofos contienen la alegría del pensar y, si se comparten entre todos, la magia se realiza (como la cadena magnética del Ión) y el pensar es alegre. Puede ocurrir también al discutir algún problema en comunidad de investigación: el pensar alegre invita a los demás a compartir la alegría, la afirmación de unos invita a los demás a afirmarse en sí mismos. Los que comparten la alegría, dice Spinoza, saben que comparten su naturaleza de modo tal que, "si, por ejemplo, dos individuos que tienen una naturaleza enteramente igual se unen entre sí, componen un individuo doblemente potente que cada uno de ellos por separado" (ÉIV18esc). Y es esta potencia compartida la que puede hacernos felices.

Claro, la felicidad, que es la virtud misma, es tan excelsa como rara (ÉV42esc). Así termina la Ética; la misma obra que, se dijo más arriba, promete la experiencia de la felicidad, parece vedarla en sus palabras finales. Pero sabemos que la experiencia es, más que el método, una invitación a lo incierto. 
Y el espíritu que la filosofía espinosana puede contribuir a la tarea en la escuela en general y a la práctica de la filosofía con niños en particular es, como se dijo más arriba, el de un puerto seguro desde donde invitar a la experiencia a la alegría del pensar.

\section{Referências bibliográficas}

BOSS, Gilbert. “L'idéal humain chez Spinoza”. En DOMÍNGUEZ, Atilano (ed.). La Ética de Spinoza. Fundamentos y significado. Ediciones de la Universidad de CastillaLa Mancha, 1992, pp. 217-232.

COROMINAS; PASCUAL. Diccionario Crítico Etimológico. Madrid, Gredos, 1991, V tomos.

HENRY, Michel. La felicidad de Spinoza. Buenos Aires, La Cebra, 2008.

LIPMAN, Matthew. La filosofía en el aula. Madrid, Ediciones de la Torre, 1992.

MISRAHI, Robert. "Le désir, l'éxistence et la joie dans la philosophie, c'est-à-dire l'Éthique de Spinoza”. En DOMÍNGUEZ, Atilano (ed.). La Ética de Spinoza. Fundamentos y significado. Ediciones de la Universidad de Castilla-La Mancha, 1992, pp. 53-64.

PASCAL, Blaise. Pensamientos. Buenos Aires, Sudamericana, 1971, 2 tomos.

SHARP, Ann; SPLITTER, Laurance. La otra educación. Filosofía para niños y comunidad de indagación. Buenos Aires, Manantial, 1995.

SPINOZA, Baruch. Ética demostrada según el orden geométrico. Madrid, Alianza, 1998, traducción de Vidal Peña García.

SPINOZA, Baruj. Ética demostrada según el orden geométrico. Madrid, Trotta, 2009, traducción de Atilano Domínguez.

SPINOZA. Tratado de la Reforma del Entendimiento. Madrid, Alianza, 1998, traducción de Atilano Domínguez.

Filosofia e Educação - ISSN 1984-9605 - Volume 5, Número 1

Abril - Setembro de 2013 